\title{
Potential of the fungus Talaromyces as biological control agent for Eichhornia crassipes in freshwater systems
}

\author{
Jesus Alfonso C. Catahay ${ }^{1}, \mathrm{O}^{\prime}$ Neil D. Cerdeña ${ }^{1}$, Gabrielle Beatrix B. Francisco ${ }^{1}$, Keisha \\ Eunice T. Geson ${ }^{1}$, Justin Paolo B. Abengaña ${ }^{2}$, Anna Christina R. Ngo ${ }^{2}$, E Gina R. Dedeles ${ }^{1-3 *}$ \\ ${ }^{1}$ Department of Biological Sciences, College of Science; ${ }^{2}$ The Graduate School; ${ }^{3}$ Research Center for the \\ Natural and Applied Sciences, University of Santo Tomas, 1015 Manila, Philippines
}

\begin{abstract}
Eichhornia crassipes infestations and its rapid thick mat formation in freshwater systems has made it as one of the major invasive weeds in the country. In this study, the potential of three fungal isolates as biological control agents for E. crassipes was assessed. Diseased $E$. crassipes leaves were collected from weed-infested sites in Los Baños, Laguna, and all emergent fungi on potato dextrose agar (PDA) plates were isolated and four were selected for the pathogenicity test following Koch's postulates. Of the 47 isolates tested, three inflicted necrosis on healthy leaves of $E$. crassipes and were phenotypically identified as Talaromyces LB018, LB032, and LB033. These three isolates exhibited similar characteristics when grown in both PDA and malt extract agar (MEA) plates. Molecular analysis of the strain LB033 revealed that it is conspecific to strain I5 and almost sequence identical to CBS 286.36 type strain, Talaromyces purpureogenus, based on its molecular data analysis from the internal transcribed spacer (ITS) region. Talaromyces is a genus of fungi in the family Trichocomaceae characterized by having soft, cottony, and loose hyphal fruiting bodies. The anamorphs are strongly similar to Penicillium which is a known biocontrol agent with diverse antagonistic properties against many other microorganisms. The results of this study can provide much-needed information on the potential of Talaromyces as biocontrol agent for E. crassipes.
\end{abstract}

Keywords: biocontrol, Eicchornia crassipes, Talaromyces, Penicillium

\section{INTRODUCTION}

Eichhornia crassipes (Mart.) Solms or commonly known as water hyacinth is an aquatic weed in the family Pontederiaceae. It is native to Brazil but is widely distributed in tropical and subtropical regions due to its optimal temperature ranging from $27^{\circ} \mathrm{C}$ to $30^{\circ} \mathrm{C}[1,2]$ (Gopal, 1987; Coetzee et al., 2011). Mature plants

*To whom correspondence should be addressed: grdedeles@yahoo.com vary in height ranging from less than a foot to a meter and can proliferate rapidly under optimal conditions as to cause massive infestations on polluted bodies of water including lakes and rivers. Problems which can arise from the accumulation of these aquatic weeds include the reduction of light and oxygen, alteration of water chemistry, the significant negative effect on natural flora and fauna, observable water reduction, obstruction of water transport and fishing activities and many more [3] (Calvert, 2002). 
Recently, the use of biocontrol agents has become an important alternative to chemicals in crop protection against weeds and insects. Plant pathogens are known to be notorious for their capabilities to create severe epidemics, provided that a source of inoculum is present along with appropriate environmental conditions and a susceptible host. Controlled experimental studies have confirmed the potential of fungi to control the spread of E. crassipes species [4, 5] (Charudattan and Dinoor, 2000; Charudattan, 2001). In a study conducted by Jimenez and Charudattan [6] (1998) Alternaria sp., Acremonium zonatum, Cercospora piaropi, Verticillium sp., and Fusarium sp. were found to be highly virulent and considered to be potential bioherbicide agents against water hyacinth.

In the Philippines, E. crassipes is one of the major environmental problems, particularly in Mindanao region. Water hyacinth infestation is also a recurring problem in Laguna de Bay, Marikina River, and some parts of Pasig River in Metro Manila. One of the severely affected areas in the Philippines is the Rio Grande River in Cotabato City, Mindanao where residents experienced one of the worst floodings in years according to a news report in 2011. Therefore, residents are finding ways to reduce the biomass of water hyacinth clogging their water systems to prevent further damages [7] (Calonzo, 2011).
The government has implemented projects such as green charcoal project, fertilizer, and basket making which are indeed helpful in reducing the biomass of E. crassipes present in freshwater systems. However, these projects only impose a short-term relief. For sustainable, long-term solution, it is necessary to make use of an approach in which biological control agents play an important role. To date, there have been no reports yet of using biological control agents in maintaining or reducing the biomass of $E$. crassipes in the country. Thus, this study identified the fungus Talaromyces as a potential biological control agent for E. crassipes in our freshwater systems.

\section{Materials AND Methodology}

Collection of E. crassipes leaf samples. Plant leaves with necrotic lesions were collected from Los Baños, Laguna (14¹0’57.1” N, 12113’28.8” E). The collected leaves were then stored in polyethylene zip-lock bags inside an ice chest upon transport to the laboratory. Plant authentication was verified at the University of Santo Tomas (UST) Herbarium. The collection site along with its map location is shown in Fig. 1.

Isolation of filamentous fungi. Leaf pieces were cut from the margins with signs of necrotic or chlorotic lesions on the leaves, then surfacedisinfected with $0.26 \%$ sodium hypochlorite

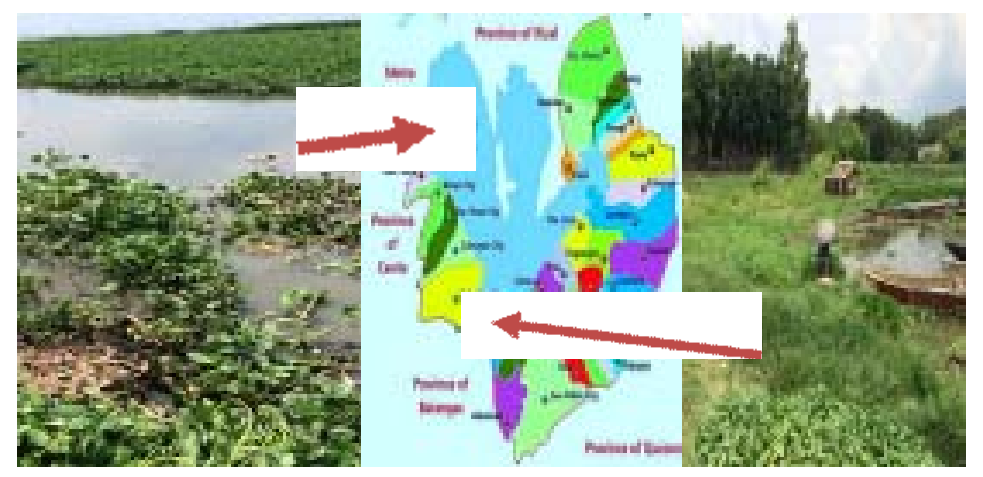

Figure 1. Collection site of E. crassipes (water hyacinth) healthy plant samples (left panel, Laguna de Bay) and those with necrotic lesions (right panel, Los Baños, Laguna). 
solution for $5 \mathrm{~min}$ and rinsed with sterile distilled water to remove traces of disinfectant. Five to six pieces were placed in Petri dishes containing half-strength TM media potato dextrose agar (PDA). This was followed by incubation at room temperature for 2-3 days. All emergent fungi were isolated and pure cultures were obtained by single-spore or agar-block technique [6] (Jimenez and Charudattan, 1998).

\section{Morphological characterization of fungal} isolates. Fresh cultures of fungi were grown on full-strength PDA and malt extract agar (MEA). Three small square-sized pieces were cut from the leading edge of the fungal growth and placed on a glass slide supported by applicator sticks set inside a Petri plate. The PDA/MEA squares were covered with a cover slip. A shallow layer of water was added to the dish to provide humidity and then maintained under sterile conditions. Replicate plates were prepared for each fungal isolate incubated at room temperature with ambient light until the cover glass had been full of mycelia. Slides were observed under high power and oil immersion objectives for spores and spore-producing structures. The identification of the fungal isolates was based on their phenotypes and then compared to descriptions in the literature on mitosporic fungi [8-11] (Tharp 1917, Chupp 1953, Ainsworth et al. 1973, Barett 1989) with assistance from a mycologist. This was followed by molecular characterization using the ITS region of one strain, LB033 using the method outlined by [12] Bennett et al. 2017.

Pathogenicity tests. Healthy E. crassipes plants were collected from Laguna de Bay, Manila $\left(4.3935^{\circ} \mathrm{N}, 121.1939^{\circ} \mathrm{E}\right)$ then washed and maintained on pots for 4 days with tap water for the adjustment period. These were maintained in a controlled environment at UST Greenhouse for 2 weeks in $3 \mathrm{~L}$ of purified water containing $50 \%$ Hoagland's solution. Leaves were inoculated with isolates by agar block technique [13] (Yang et al. 1991) using an 8 mm cork borer to pierce through a 5-day old full strength PDA medium containing the fungal isolates to be tested. Application of the agar block to the leaf was aseptically transferred using an inoculating loop to achieve direct contact to the leaf. Hoagland's solution was replaced twice within 2-week period.

Grid method. After 7 and 14 days of inoculation, the isolates were evaluated for their ability to cause disease using a grid method, which has a $10 \times 10 \mathrm{~cm}$ grid placed above the necrotic lesions of a leaf. The total number of boxes occupied by necrosis on the leaf surface was counted and recorded. The criteria considered in counting the necrosis using this grid method must have at least $25-50 \%$ of the boxes reached in order to be counted as 1 . The formula used to assess their ability to cause disease is:

$$
\left(\sum \text { Leaf } A\right)+\left(\sum \text { Leaf B }\right)+\left(\sum \text { Leaf } C\right) / 3
$$

where, the $\sum$ leaf is the number of boxes occupied by necrosis on experimental leaf.

A single-factor ANOVA was utilized in order to determine if there was a significant difference among the values gathered using this type of evaluation. The $p$ value was also determined in ANOVA to prove further that the data were statistically valid.

\section{RESUlTS AND DISCUSSION}

Many fresh bodies of water, especially in the Philippines, are infested with water hyacinth as the plant multiplies rapidly, clogging irrigations and water systems needed for the daily cycle of life. The most common method of removal for these water hyacinths is by physical method which requires machines or equipment that can separate aggregates of the plants and remove them from the infested body of water.

Fungal pathogens may cause diseases in humans and other organisms such as plants [14] (San-Blas and Calderon, 2008). The use of fungal 
pathogens as biological control agents for water hyacinth shows a potential to effectively eliminate invasive plant species. In the Philippines, there have been no reports yet of using biological control agents especially with the use of fungal pathogens in reducing the biomass of water hyacinths. Therefore, this study aimed to explore the potential use of these fungal pathogens as biocontrol agents for water hyacinth.

A forty-seven fungal strains were isolated from diseased E. crassipes plants, however, only three of these were found capable of inflicting necrosis on healthy plant samples. All other caused neither chlorotic nor necrotic lesions on inoculated plants. Many of the latter fungi belong to the genera Colletotrichum, Trichoderma, and Aspergillus which are common inhabitants of plants and are also known to be ubiquitous in the environment. The three fungal isolates (LB018, LB032, and LB033) positive in pathogenicity test were initially identified up to the genus level based on the morphology of their conidia or mycelia. As observed, these isolates exhibited similar biverticillate conidiophores and thus, were identified as Talaromyces spp. Anamorphs strongly similar to Penicillium spp. which were difficult to distinguish from each other. Colonies of Talaromyces LB018, for example, were distinctly circular, flat and dark green with orange margin on PDA, but irregular and orange with white margin on MEA. Followed by molecular (ITS region) characterization, it was established that one of the three isolates, LB033 was conspecific to Talaromyces purpureogenus CBS 286.36 (Fig. 2).

Several studies have established Talaromyces strains as plant pathogens [15-19] (Marois et al 1984; Naraghi et al. 2010a-b; Kato et al. 2012ab). To consider an organism as an effective plant pathogen, it must possess characteristics that make them desirable candidates as biological control agents for aquatic weeds. Such

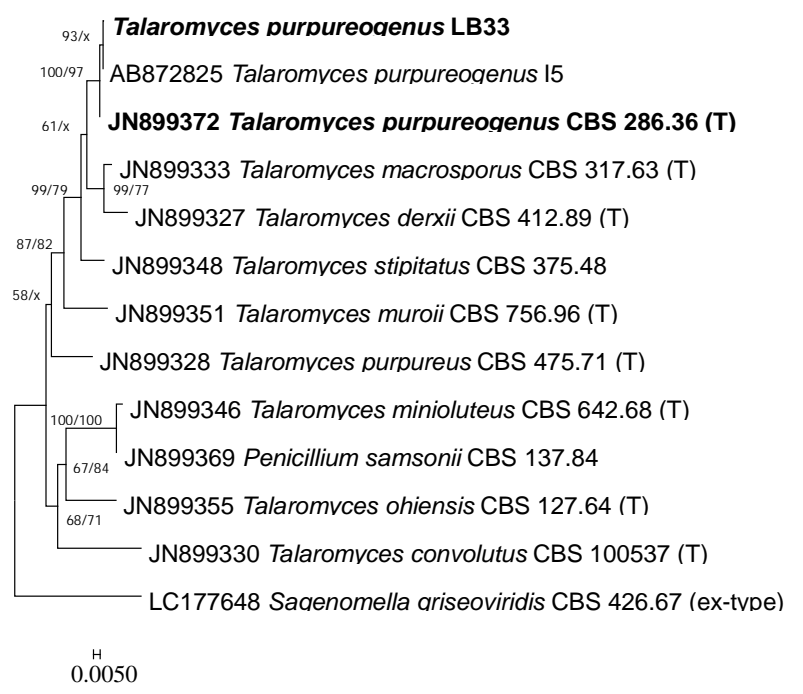

Figure 2. Talaromyces spp. based on internal transcribed spacers. Based on minimum evolution (primary tree computation), strain LB033 is conspecific to strain I5 and almost sequence identical to CBS 286.36 (type specimen). Whereas, the three strains are conspecific based on maximum likelihood (secondary tree computation) with strong bootstrap support. Since the nucleotide sequence divergence of strain LB033 to CBS 286.36 is low, and that conspecificity is highly supported using maximum likelihood analysis, strain LB033 is identified as T. purpureogenus. () Indicates bootstrap value lower than 50 . Scale bar $=$ number of nucleotide substitutions. 
characteristics include their abundance and diversity; host-specificity to the target plant to avoid damage to other non-invasive species found in the same environment; possible dissemination into areas of infestation and is self-maintaining; capability of limiting populations without eliminating the species; and lastly, must be non-pathogenic to animals [20] (Martyn and Freeman, 1978).

The pathogenicity test done in this study was by the application of Koch's Postulates [21] (Hettiarachchi et al. 1983) and cross-section examination of healthy and infected leaves to ensure that necrosis was eventually caused by the isolates of Talaromyces. Evaluation of their pathogenicity was observed for 14 days after inoculation of a 5-day old fungal agar block on living and healthy E. crassipes plants. The experiment was done on days 0,7 , and 14 , then were observed for the development of necrosis around the agar block. Figure 3 shows the experimental results gathered after 14 days of observation. In this figure, a positive result (A) indicated by the presence of necrosis on the surface around the agar block means that the fungal isolate was pathogenic on E. crassipes leaf. In contrast, the absence of necrosis on the leaf surface after 14 days (B) was an indication of a negative result, suggesting that the fungal isolate was not pathogenic to the plant. An uninoculated leaf (C) was also added to serve as the control variable throughout the investigation.

Other than the physical observation of necrosis around the agar block, the grid method as shown in Table below was used to provide an estimation of the development of necrosis. Studies involving the evaluation of necrosis on plants inflicted by fungal isolates more often described their pathogenicity as positive and negative only [21-23] (Hettiarachchi et al. 1983, Charudattan 1986, Shabana et al. 1997). Following the grid method, isolate Talaromyces LB018 was able to produce the highest degree of necrosis, occupying an average of 13 boxes from the grid after 14 days (Table). This method provides an

Estimated number of boxes occupied by fungal necrosis on the plant leaf surface

\begin{tabular}{l|c}
\hline \multicolumn{1}{c|}{ Isolate ID } & $\begin{array}{c}\text { Average number } \\
\text { of boxes around } \\
\text { necrotic lesions }\end{array}$ \\
\hline Talaromyces sp (LB018) & 13 \\
Talaromyces sp. (LB032) & 10 \\
Talaromyces purpureogenus (LB033) & 8 \\
\hline
\end{tabular}

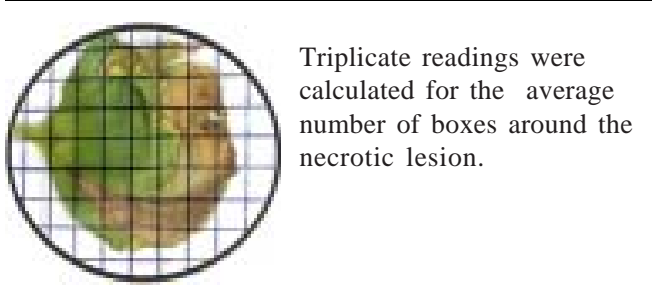

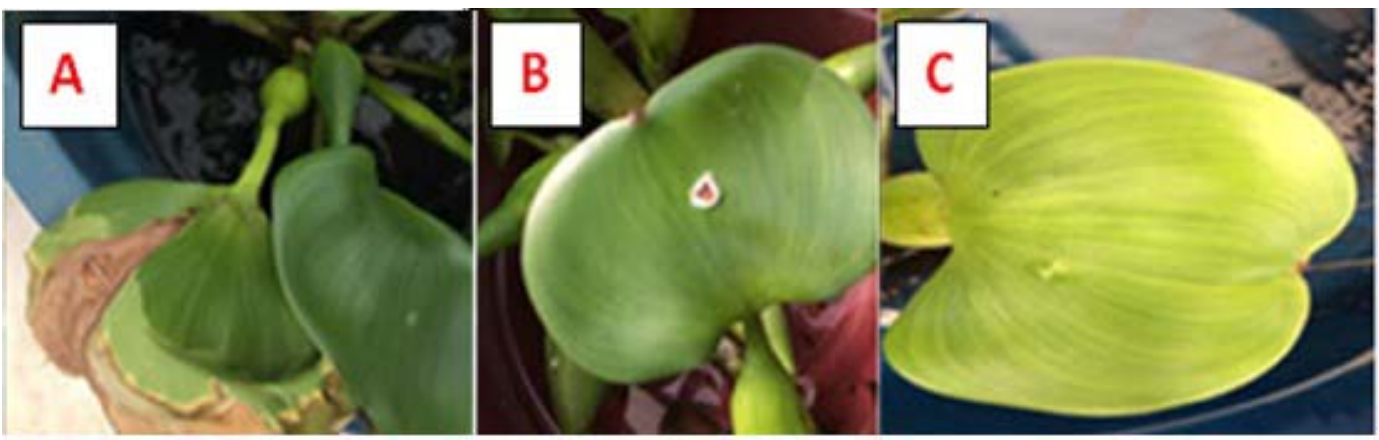

Figure 3. Pathogenicity tests of fungal isolates on healthy E. crassipes leaves (A) Positive, Talaromyces sp. (LB018), (B) Negative, Colletotrichum sp (LB014) and (C) Control. An arrow shows necrosis on the leaf surface around the agar block as evidently shown in (A), indicating that the fungal isolate was pathogenic to the plant; while no signs of necrosis was found around the agar block (arrow) in (B) and on the entire surface of the control leaf $(\mathrm{C})$. 


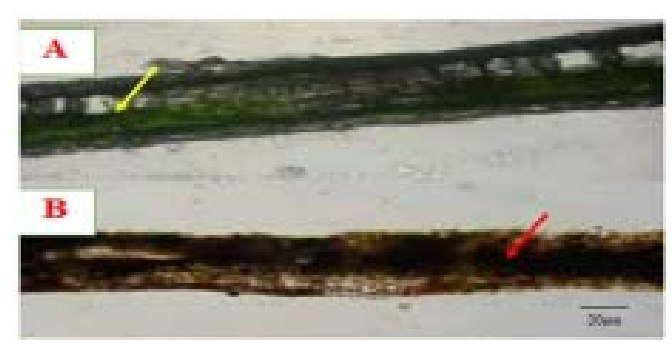

Figure 4. Cross section of E. crassipes healthy leaf tissue (A) pointed by a white arrow and the infected tissue (B) pointed by a black arrow.

easier way to compare the level of pathogenicity observed on E. crassipes leaves. The estimation was entirely based on the average total number of boxes occupied by necrotic lesion on the leaf surface and validated by using ANOVA single factor data analysis. Statistical analysis showed that there was no significant differences in the values obtained for each isolate.

The cross section of an infected leaf was also observed to determine the depth of infection caused by Talaromyces LB018. As shown in Fig. 4 , it is clearly visible that the fungal isolate was able to reach the deep tissues of the leaf. Comparing both the interiors of the healthy and diseased leaf, the difference between their conditions was clearly distinguished. Death of plant tissues (shown by black arrow) in the infected leaf was ascertained by necrosis in its interior (B) while the uninfected healthy leaf tissues (A) exhibited still greenish coloration (pointed by white arrow) and absence of necrosis was apparent.

Furthermore, in accordance to Koch's Postulates, the leaves which exhibited necrosis after 14 days were used as explants for the reisolation of the fungal isolates. In this course of study, Koch's postulate was successfully fulfilled and the identity of the isolates was verified.

Death of tissues as a result of necrosis can be caused by many factors such as fungal, bacterial, and environmental factors [24](Bachmair et al. 1990). Results in this study indicates that necrosis was not of bacterial origin due to the fulfillment of Koch's postulates nor was it caused by environmental factors such as heat and dryness [25] (Bouchereau et al. 1999). In addition, nutrient deficiency can also be a factor resulting to the death of internal tissues. However, in this study the setups were supplied by complete nutrients due to the application of Hoagland's solution, thus showing that the observed tissue death in the cross-section of the infected leaf was not caused by the loss of nutrients, bacteria, or other environmental factors but as a consequence of fungal inoculation on the leaf.

Thus, it is prudent that for further studies on this work, the combination of fungal pathogens or consortia be tested along with the evaluation of their synergistic activities, extraction and detection of metabolites using different media and mass production of the identified metabolites.

\section{ACKNOWLEDGements}

This research would not have been possible without the resources of the UST Research Center for the Natural and Applied Sciences (RCNAS) and of Reuel M. Bennett who performed the molecular analysis of LB033.

\section{REFERENCES}

[1] Gopal B. Water hyacinth. (Amsterdam: Elsevier Science Publishers, 1987).

[2] Coetzee JA, Hill MP, Byrne MJ, Bownes A. A Review of the biological control programmes on Eichhornia crassipes (C.Mart.) Solms (Pontederiaceae), Salvinia molesta D.S.Mitch. (Salviniaceae), Pistia stratiotes L. (Araceae), Myriophyllum aquaticum (Vell.) Verdc. (Haloragaceae) and Azolla filiculoides Lam. (Azollaceae) in South Africa. African Entomology 2011; 19:451-68. 
[3] Calvert P. Water hyacinth control and possible uses (Technical brief). (UK: International Technology Development Center, 2002). http:// ow.ly/Tjgp.

[4] Charudattan R, Dinoor A. Biological control of weeds using plant pathogens: accomplishments and limitations. Crop Protection 2000; 19(8):69195.

[5] Charudattan R.Biological Control of Water Hyacinth by Using Pathogens: Opportunities, Challenges, and Recent Developments. Biological and Integrated Control of Water Hyacinth, Eichhornia crassipes (Proceedings of the Second Meeting of the Global Working Group for the Biological and Integrated Control of Water Hyacinth, Beijing, China, October 9 11, 2001), pp. 21-28.

[6] Jimenez M, Charudattan R. Survey and evaluation of Mexican native fungi for potential biocontrol of water hyacinth. Journal of Aquatic Plant Management 1998; 36:145-48.

[7] Calonzo A. River-clogging plant causes devastating Cotabato flood 2011. www.gmanetwork (October 24, 2015).

[8] Tharp B. Texas parasitic fungi. Mycologia 1917; 9:105-24.

[9] Chupp C. A monograph of the fungus Genus Cercospora 1953. (Ithaca, NY, 667).

[10] Ainsworth G, Sparrow F, Sussman A. The Fungi (Vol. IV-A), p. 621. (New York: Academic Press, 1973).

[11] Barrett SC. Waterweed invasions. Scientific American 1989; 260:90-97.

[12] Bennett RM, Dedeles GR, Thines M. Phytophthora elongata (Peronosporaceae) is present as an estuarine species in Philippine mangroves. Mycosphere 2017; (8)7:956-67.

[13] Yang S, Dowler W, Johnson R. Comparison of methods for selecting fungi pathogenic to leafy spurge. Plant Disease 1991; 75(12):1201-03.

[14] San-Blas G, Calderone RA. Pathogenic fungi: insights in molecular biology. Caister Academic Press, 2008.

[15] Marois J, Fravel D, Papavizas G. Ability of Talaromyces flavus to occupy the rhizosphere and its interaction with Verticillium dahliae. Soil Biology and Biochemistry 1984; 16:387-390.
[16] Naraghi L, Heydari A, Rezaee S, Razavi M, Jahanifar $\mathrm{H}$. Study on antagonistic effects of Talaromyces flavus on Verticillium albo-atrum, the causal agent of potato wilt disease. Crop Protection 2010a; 29:658-62.

[17] Naraghi L, Heydari A, Rezaee S, Razavi M. Biocontrol agent Talaromyces flavus stimulates the growth of cotton and potato. Journal of Plant Growth Regulation 2012b; 31:471-77.

[18] Kato A, Miyake T, Nishigata K, Tateishi H, Teraoka $\mathrm{T}$, Arie $\mathrm{T}$. Use of fluorescent proteins to visualize interactions between the Bakanae disease pathogen Gibberella fujikuroi and the biocontrol agent Talaromyces sp. KNB-422. Journal of General Plant Pathology 2012a; 78:54-61.

[19] Kato A, Miyake T, Tateishi H, Teraoka T, Arie T. Mode of action of Talaromyces sp. KNB422, a biocontrol agent against rice seedling diseases. Journal of Pesticide Science 2012b; 37:56-61.

[20] Martyn R, Freeman T. Evaluation of Acremonium zonatum as a potential biocontrol agent of water hyacinth. Plant Disease Reports 1978; 62:60408.

[21] Hettiarachchi S, Gunasekera SA, Balasooriya I. Leaf spot diseases in water hyacinth found in Sri Lanka. Journal of Aquatic Plant Management 1983; 21:62-65.

[22] Charudattan R. Cercospora rodmannii: a biological control agent for water hyacinth. Aquatics 1986; 8(2):21-24.

[23] Shabana YM, Baka ZA, Abdel-Fattah GM. Alternaria eichhorniae, a biological control agent for water hyacinth: mycoherbicidal formulation and physiological and ultrastructural host responses. European Journal of Plant Pathology 1997; 103:99-111.

[24] Bachmair A, Becker F, Masterson RV, Schell J. Perturbation of the ubiquitin system causes leaf curling, vascular tissue alterations and necrotic lesions in a higher plant. European Molecular Biology Organization Journal 1990; 13:4543549.

[25] Bouchereau A, Aziz A, Larher F, Martin-Tanguy J. Polyamines and environmental challenges: recent development. Plant Science 1999; 140(2):103-25. 